\section{Folfox encephalopathy: A rare case series}

\section{DOI: $10.4103 / 2278-330 X .208850$}

Dear Editor,

Encephalopathy is a rare and usually reversible toxicity following FOLFOX 4, a well-established and well-tolerated chemotherapeutic regimen for gastrointestinal cancers. We report two cases of encephalopathy occurring after FOLFOX4 chemotherapy presented with confused mental status and recovered completely.

\section{Case Report I}

A 37-year-old woman diagnosed with carcinoma colon. with Krukenbergs tumor was started on FOLFOX 4 regimen. During infusion of 5-flourouracil (FU), the patient developed severe headache, intractable vomiting. Subsequently, she became drowsy, developed altered sensorium, and aphasia. She also developed bilateral ptosis, hypertension. Magnetic resonance imaging (MRI) was done which was suggestive of acute toxic encephalopathy [Figure 1]. Toxic and metabolic screen was negative. An electroencephalogram showed a diffuse slowing of waves. Two-dimensional (2D) echo showed ejection fraction of $40 \%$, compared to baseline of $58 \%$ before starting chemotherapy. The patient was started on intravenous methyl prednisolone, lactulose enema, hydration, and oxygen support. After 7 days, her ptosis and sensorium gradually improved but improvement in speech from incomprehensible sounds through monosyllable speech to normal speech took about 14 days. MRI and 2D echo at the time of discharge were normal.

\section{Case Report 2}

A 55-year-old patient of carcinoma esophagus, on disease progression was started on FOLFOX-based chemotherapy. She tolerated the first three cycles of chemotherapy fairly well. However, on $5^{\text {th }}$ day of cycle four, she presented to emergency room with the complaints of altered sensorium and hypertension. Investigations revealed increased creatinine, decreased left ventricular ejection fraction (27\%). An MRI brain was suggestive of acute toxic encephalopathy [Figure 2]. She was treated with antihypertensives and other supportive

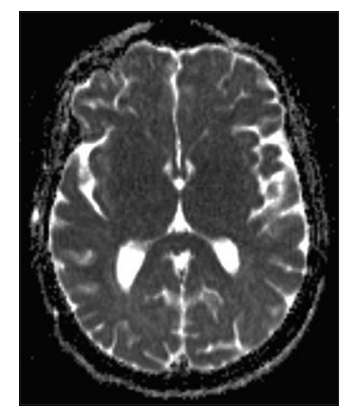

Figure 1: Case 1: Diffusion-weighted magnetic resonance imaging showing diffusion restriction in bilateral subcortical white matter South Asian Journal of Cancer • Volume 6 •Issue 2 • April-June 2017 


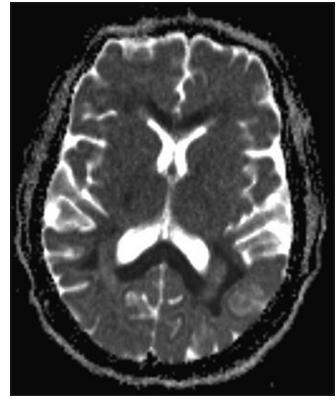

Figure 2: Case 2: Bilateral symmetrical cerebral white matter diffusion restriction

care. Gradually, her kidney function tests normalized, and her sensorium normalized within 72 hours.

\section{Discussion}

Encephalopathy can occur as an adverse effect of FOLFOX regimen in $5.7 \% .^{[1]}$ This can be of three different types. They are posterior reversible encephalopathy, Wernicke's encephalopathy, and hyperammonemic encephalopathy. ${ }^{[2,3]}$ It is the diagnosis of exclusion.

When 5-FU-induced encephalopathy is suspected, the immediate step is to stop 5-FU infusion. Laboratory tests include but not limited to serum electrolytes, serum ammonia levels, kidney, and liver function tests. MRI is the imaging modality of choice. ${ }^{[4]}$

In most cases, patients recovered completely after supportive treatment. Our patient was treated with intravenous methyl prednisolone, hydration, branched chain amino acid infusions, and lactulose enema.

\section{Conclusion}

Removal of the cytotoxic drug is usually recommended once encephalopathy occurs. Early diagnosis and treatment play a pivotal role in the management of FOLFOX-induced encephalopathy as it is a reversible condition with good supportive care.

\section{Financial support and sponsorship}

Nil.

\section{Conflicts of interest}

There are no conflicts of interest.

Ullas Batra,Venkata Pradeep Babu Koyyala,Akhil Jain, Chaturbhuj Agrawal, Udip Maheswari

Department of Medical Oncology, Rajiv Gandhi Cancer Institute and Research Centre, New Delhi, India Correspondence to: Dr. Ullas Batra,

\section{References}

1. Hinchey J, Chaves C, Appignani B, Breen J, Pao L, Wang A, et al. A reversible posterior leukoencephalopathy syndrome. N Engl J Med 1996;334:494-500.

2. Bartynski WS. Posterior reversible encephalopathy syndrome, part 1 : Fundamental imaging and clinical features. AJNR Am J Neuroradiol 2008;29:1036-42.

3. Kim $\mathrm{CH}$, Kim CH, Chung $\mathrm{CK}$, Jahng TA. Unexpected seizure attack in a patient with spinal metastasis diagnosed as posterior reversible encephalopathy syndrome. J Korean Neurosurg Soc 2011;50:60-3.

4. Bartynski WS, Boardman JF. Distinct imaging patterns and lesion distribution in posterior reversible encephalopathy syndrome. AJNR Am J Neuroradiol 2007;28:1320-7.

This is an open access article distributed under the terms of the Creative Commons Attribution-NonCommercial-ShareAlike 3.0 License, which allows others to remix tweak, and build upon the work non-commercially, as long as the author is credited and the new creations are licensed under the identical terms.

How to cite this article: Batra U, Koyyala VP, Jain A, Agrawal C, Maheswari U Folfox encephalopathy: A rare case series. South Asian J Cancer 2017;6:86-7.

(C) 2017 The South Asian Journal of Cancer | Published by Wolters Kluwer - Medknow 